\title{
Ten-Year Secular Trends in Youth Violence: Results From the Philadelphia Youth Risk Behavior Survey 2003-2013
}

Andrew C. Pool, MSc a Freda Patterson, PhD, MS ${ }^{b}$ Ingrid Y. Luna, MPH“c Bernadette Hohl, PhD, MPHd Katherine W. Bauer, PhD, MS

\section{ABSTRACT}

BACKGROUND: Youth violence reduction is a public health priority, yet few studies have examined secular trends in violence among urban youth, who may be particularly vulnerable to numerous forms of violence. This study examines 10-year secular trends in the prevalence of violence-related behaviors among Philadelphia high school students.

METHODS: Repeated cross-sectional data were analyzed from 5 waves of the Philadelphia Youth Risk Behavior Survey (YRBS) from 2003 to 2013. Sex-specific multivariate regression models were used to examine secular trends in multiple types of violence, accounting for age, race/ethnicity, and sampling strategy.

RESULTS: In 2013, the most prevalent violent behavior was physical fighting among boys (38.4\%) and girls (32.7\%). Among girls, the prevalence of sexual assault and suicide attempts declined between 2003 and $2013(\beta=-0.13, \mathrm{p}=.04$ and $\beta=-0.14$, $\mathrm{p}=.007$, respectively). Among boys, significant declines in carrying a weapon $(\beta=-0.31, \mathrm{p}<.001)$, carrying a gun $(\beta=-0.16$, $\mathrm{p}=.01)$, and physical fighting $(\beta=-0.35, \mathrm{p}=.001)$ were observed.

CONCLUSIONS: Whereas the prevalence of some forms of violence stabilized or declined among Philadelphia youth during 2003-2013 time span, involvement in violence-related behaviors remains common among this population. Continued surveillance and evidence-based violence reduction strategies are needed to address violence among urban youth.

Keywords: youth violence; youth risk behaviors; adolescent health; firearms.

Citation: Pool AC, Patterson F, Luna IY, Hohl B, Bauer KW. Ten-year secular trends in youth violence: results from the Philadelphia Youth Risk Behavior Survey 2003-2013. J Sch Health. 2017; 87: 244-252.

Received on September 11, 2015

Accepted on October 13, 2016

$\mathrm{D}$ espite declines in the prevalence of youth violence in the United States in the past 2 decades, ${ }^{1}$ violence among adolescents remains a public health priority. ${ }^{2}$ Youth violence is a major contributor to morbidity and mortality in the United States. For example, interpersonal violence accounts for over 4000 deaths among people between the ages of 15 and 24 in the United States annually and is the third leading cause of death among this age group. ${ }^{3}$ Acts of self-directed violence are also highly prevalent among this age group, with suicide accounting for nearly 5000 deaths among 15- to 24-year-olds in
2013. ${ }^{3}$ Involvement in violence-related behaviors has long-lasting health impacts beyond the direct harm induced by the violent act including increased risk of cardiovascular disease, ${ }^{4,5}$ posttraumatic stress disorder, ${ }^{6}$ major depression, and substance abuse. ${ }^{7}$ As a means to promote innovative violence reduction interventions, Healthy People 2020 (HP 2020) has set specific objectives of $10 \%$ reductions in physical fighting among adolescents and children's exposure to violence. ${ }^{2}$

Nationwide surveillance of youth violence provides essential information regarding broad secular trends (ie

aDDoctoral Candidate, (andrew.pool@temple.edu), Center for Obesity Research and Education (CORE), Temple University, 3223 North Broad Street, Suite 175, Philadelphia, PA 19140. ${ }^{\text {b} A s s i s t a n t ~ P r o f e s s o r, ~(f r e d a p @ U D e l . e d u), ~ D e p a r t m e n t ~ o f ~ B e h a v i o r a l ~ H e a l t h ~ a n d ~ N u t r i t i o n, ~ U n i v e r s i t y ~ o f ~ D e l a w a r e, ~ C o l l e g e ~ o f ~ H e a l t h ~ S c i e n c e s, ~} 26$ Carpenter Sports Building, Newark, DE 19122.

‘Graduate Student, (ingrid.luna227@gmail.com), Department of Social and Behavioral Sciences, Temple University, College of Public Health, 1301 Cecil B Moore Avenue, 966 Ritter Annex, Philadelphia, PA 19122.

dInstructor, (bernadette.hohl@rutgers.edu), Department of Epidemiology, Rutgers University, School of Public Health, 683 Hoes Lane West, Piscataway, NJ 08854.

eAssistant Professor, (kwbauer@umich.edu), Department of Nutritional Sciences, University of Michigan, School of Public Health, 1415 Washington Heights, Ann Arbor, MI 48109.

Address correspondence to: Andrew C. Pool, Doctoral Candidate, (andrew.pool@temple.edu), Department of Social and Behavioral Sciences, Temple University, Center for Obesity Research and Education (CORE), 3223 North Broad Street, Suite 175, Philadelphia, PA 19140.

The authors thank all the principals, staff members, and students from the School District of Philadelphia who participated in this study. 
the long-term occurrence of an outcome), and informs general violence reduction goals, such as HP 2020. However, these macro-level examinations may not be representative of trends in youth violence among specific populations and within specific high-risk localities. Compared to suburban youth, urban youth may be disproportionally affected by the economic, health, and academic consequences of violence given the clustering of multiple types of violence in communities, a greater overall accumulation of life stressors, and a lack of resources that promote resiliency. ${ }^{8,9}$ Qualitative studies have identified the breadth and context of common violent experiences among urban youth that are not typically captured by nationwide surveillance efforts. For example, school safety, personal victimization and neighborhood crime, violence, and death were identified as common childhood adverse exposures among low-income Philadelphia adolescents. ${ }^{10}$ Further, local-level examinations of trends in youth violence may elucidate context-specific protective and risk factors for youth violence, which can be informed by the local environment. Trends in a specific type of violence may be especially striking due to a new policy or change in the physical environment within a specific geographic area. Conducting comprehensive type- and venue-specific surveillance of violence among high-risk populations, such as urban youth, is essential to identify gaps in current violence prevention programming, understand how demographic or other community-level changes may influence youth involvement in violence, and ultimately improve the health of highly vulnerable populations.

Self-directed violence among urban, minority youth in particular, is a type of violence that is poorly understood. Suicidal behavior is traditionally thought to be uncommon in this population because of frequent misclassification of suicide as an accident, the high prevalence of protective factors such as religiosity, underreporting due to stigma, ${ }^{1-13}$ and less disclosure of suicidal ideation among minority youth compared to their white counterparts. ${ }^{14}$ Despite this belief that suicidal behavior is not prevalent among minority youth, evidence from the national Youth Risk Behavior Survey (YRBS) indicates that a higher proportion of black and Hispanic high school students report attempting suicide than white students. ${ }^{1}$ Some local-level examinations of urban youth have replicated these results, ${ }^{15,16}$ but others have not found differences in the prevalence of suicidal behavior by race/ethnicity. ${ }^{17}$ Further research is needed to understand self-directed violence among urban, minority youth and how it may be changing over time, in particular.

Sexual assault is another form of violence that has significant negative short- and long-term health implications including contributing to posttraumatic stress disorder and major depression. ${ }^{18}$ Nationally, sexual assault is highly prevalent among adolescents, with some estimates suggesting that adolescents are more likely than individuals of any other age group to experience sexual assault. ${ }^{19}$ Among nationally representative samples, $12 \%$ of adolescent girls and $4 \%$ of adolescent boys experience some form of sexual assault. ${ }^{18,20,21}$ A few studies have suggested that the prevalence of sexual assault is even higher among urban youth than their suburban and rural counterparts. ${ }^{17,22-24}$ Given these previous findings, it is especially important to identify and evaluate trends in this form of violence among urban youth to target future interventions to those youth at greatest risk of perpetration and victimization and evaluate the potential effectiveness of current prevention programs.

Given the lack of knowledge about the trends in multiple types of violent behaviors among urban youth the goal of this study is to examine 10-year secular trends in the prevalence of self-reported violencerelated behaviors in schools and communities, selfdirected violence, and sexual assault among 9th to 12 th grade students in Philadelphia. Philadelphia is a large metropolitan city with over 1.5 million residents, of which nearly one fourth are under the age of 18 years. ${ }^{25}$ It has a racially diverse population with $43 \%$ of the population identifying as African American and $12 \%$ identifying as Hispanic. Approximately $26 \%$ of Philadelphia residents reside in poverty. ${ }^{25,26}$ Several strategies have been implemented over the past decade to prevent and reduce youth violence in Philadelphia. ${ }^{27}$ However, to date, there has not been a comprehensive assessment of involvement in violence among this population.

\section{METHODS}

\section{Participants}

This study uses weighted data collected for the Philadelphia YRBS in $2003(\mathrm{~N}=1455), 2007$ $(\mathrm{N}=2360), 2009(\mathrm{~N}=1287), 2011(\mathrm{~N}=1475)$, and $2013(\mathrm{~N}=1227)$. Data from 2005 were excluded because weighted data are not available from the Philadelphia YRBS for that year. All students in sampled classes are eligible to participate. Parental opt out forms are sent home at least 1 week before survey administration. On the day of survey administration, data collectors explain the survey to the students, and those whose parents opted out or who did not want to participate were not given a survey. Thus, parental consent and child assent was obtained for each participant. In each of the data collection years, the school participation rate was $\geq 76 \%$ and, within the schools, the student response rate ranged from $73 \%$ in 2013 to $78 \%$ in 2011 . Girls comprised approximately $55 \%$ of the study sample across all study years (Table 1). Approximately, half of the sample was African American $\mathbf{5 4 . 6 \%}$ in 2003 and 
Table 1. Demographic Characteristics of the Participating High School Students, Philadelphia Youth Risk Behavior Survey, 2003-2013

\begin{tabular}{|c|c|c|c|c|c|c|c|c|c|c|c|c|c|c|c|}
\hline & \multicolumn{3}{|c|}{2003} & \multicolumn{3}{|c|}{2007} & \multicolumn{3}{|c|}{2009} & \multicolumn{3}{|c|}{2011} & \multicolumn{3}{|c|}{2013} \\
\hline & \multicolumn{3}{|c|}{$\begin{array}{l}\text { Weighted } \\
\text { Estimate }\end{array}$} & \multicolumn{3}{|c|}{$\begin{array}{l}\text { Weighted } \\
\text { Estimate }\end{array}$} & \multicolumn{3}{|c|}{$\begin{array}{l}\text { Weighted } \\
\text { Estimate }\end{array}$} & \multicolumn{3}{|c|}{$\begin{array}{l}\text { Weighted } \\
\text { Estimate }\end{array}$} & \multicolumn{3}{|c|}{$\begin{array}{l}\text { Weighted } \\
\text { Estimate }\end{array}$} \\
\hline & Count* & $* \quad(S D)$ & $\%$ & Count* & $\quad(S D)$ & $\%$ & Count* & * $\quad$ (SD) & $\%$ & Count* & * $\quad(S D)$ & $\%$ & Count* & (SD) & $\%$ \\
\hline Total & 14555 & $54,972(4734)$ & - & 2360 & 45,267 (2948) & - & 1287 & $42,452(4356)$ & - & 1475 & $41,870(1801)$ & - & 12273 & 33,837 (3588) & - \\
\hline \multicolumn{16}{|c|}{ 等 } \\
\hline Female & 8052 & 27,718 (2758) & 55.3 & 13052 & 25,441 (1992) & 55.3 & 7172 & 21,903 (2391) & 55.7 & 787 & 21,135 (1218) & 53.4 & 6701 & 16,786 (1997) & 54.7 \\
\hline Male & 502 & $27,254(2625)$ & 44.7 & 1055 & 19,826 (1472) & 44.7 & 5702 & 20,549 (2301) & 44.3 & 688 & 20,734 ( & 46.7 & $557 \quad 1$ & 17,051 (1985) & 45.4 \\
\hline \multicolumn{16}{|l|}{ Age (years) } \\
\hline$\leq 14$ & 166 & 9011 (2221) & 11.4 & 199 & 4045 (724) & 8.4 & 71 & 3304 (779) & 5.5 & 153 & 4398 (785) & 10.5 & 96 & 3223 (864) & 7.8 \\
\hline 15 & 3211 & 14,812 (2049) & 22.1 & 6241 & 11,557 (1642) & 26.4 & 288 & 11,432 (2030) & 22.4 & 355 & 10,395 (1217) & 24.1 & 271 & $8272(1461)$ & 22.1 \\
\hline 16 & 4031 & $14,472(1644)$ & 27.7 & 7181 & 12,807 (1227) & 30.4 & 407 & 11,447 (1538) & 31.6 & 378 & $10,952(1136)$ & 25.6 & 382 & 9103 (1117) & 31.1 \\
\hline 17 & 3801 & $11,074(1502)$ & 26.1 & 5831 & 11,710 (1410) & 24.7 & 362 & 9438 (1198) & 28.1 & 341 & 8938 (917) & 23.1 & 287 & 7403 (1104) & 23.4 \\
\hline$\geq 18$ & 185 & $5603(1041)$ & 12.7 & 236 & 5147 (792) & 10.0 & 159 & 6831 (1643) & 12.4 & 248 & 7186 (1009) & 16.8 & 191 & 5836 (1072) & 15.6 \\
\hline \multicolumn{16}{|l|}{ Race/ethnicity } \\
\hline African American & 7953 & 36,092 (3935) & 54.6 & 13332 & 24,565 (1661) & 56.5 & 7002 & $27,511(2961)$ & 54.4 & 7952 & $25,591(1445)$ & 53.9 & 5761 & $19,412(2761)$ & 46.9 \\
\hline Non-Hispanic White & 225 & 9054 (1577) & 15.5 & 307 & $5851(980)$ & 13.0 & 157 & $5415(1016)$ & 12.2 & 178 & $5517(677)$ & 12.1 & 163 & 4921 (1153) & 13.3 \\
\hline Asian & 96 & $1373(329)$ & 6.6 & 207 & 3865 (728) & 8.8 & 97 & $1820(358)$ & 7.5 & 139 & $2231(253)$ & 9.4 & 124 & $2099(435)$ & 10.1 \\
\hline Hispanic & 211 & $6326(924)$ & 14.5 & 164 & 3847 (723) & 6.9 & 113 & $2684(547)$ & 8.8 & 110 & 2721 (372) & 7.5 & 101 & $2169(420)$ & 8.2 \\
\hline Other & 128 & $2126(311)$ & 8.8 & 349 & $7139(710)$ & 14.8 & 220 & $5022(666)$ & 17.0 & 253 & $5810(582)$ & 17.0 & 263 & $5236(660)$ & 21.4 \\
\hline
\end{tabular}

*Unweighted count.

$46.9 \%$ in 2013) and the proportion of non-Hispanic white students ranged from $12.1 \%$ in 2011 to $15.5 \%$ in 2003. Approximately, $20 \%$ of participants identified as multiracial or with race/ethnicity other than African American/black, white, or Hispanic in any given survey year. Less than $9 \%$ of the sample was Hispanic.

\section{Instruments}

The YRBS is a self-reported survey of US high school students, administered biennially at the national level by the United States Centers for Disease Control and Prevention (CDC) and at the local level by departments of health and education. ${ }^{28}$ Students complete the computer-scan questionnaire in pencil during 1-class period. In Philadelphia, the survey is administered by the School District of Philadelphia and weighted results are provided to the research community if the overall response rate is at least $60 \% .{ }^{29}$ The surveys use a 2-stage cluster design to obtain a representative study sample after weighting. Thus, if the overall response rate is greater than $60 \%$ then the study results can be generalized to all students in grades 9-12 in Philadelphia. ${ }^{30}$ Six categories of priority health-risk behaviors are monitored in the Philadelphia YRBS: behaviors relating to injuries and violence, sexual risk behaviors, tobacco use, alcohol and other drug use, unhealthy diet and physical inactivity. ${ }^{28}$

Responses to 11 total questions were examined in this study to determine prevalence of violence-related behaviors. The prevalence of recent involvement in community-based violence was assessed using 3 items: (1) "During the past 30 days, on how many days did you carry a weapon such as a gun, knife, or club?" (2)
"During the past 30 days, on how many days did you carry a gun?" and (3) "During the past 12 months, how many times were you in a physical fight?" Responses to these items were dichotomized so that any response of 1 or more days for carrying a weapon or gun, or 1 or more physical fights was coded as "yes" while reporting 0 days of weapon or gun carrying, or zero physical fights, was coded as "no."

The prevalence of school-based violence was measured using 4 items: (1) "During the past 30 days, on how many days did you carry a weapon such as a gun, knife, or club on school property?" (2) "During the past 12 months, how many times has someone threatened or injured you with a weapon such as a gun, knife, or club on school property?" (3) "During the past 12 months, how many times were you in a physical fight on school property?" and (4) "During the past 30 days, on how many days did you not go to school because you felt you would be unsafe at school on your way to or from school?" Item (4) was not asked in 2013. Responses for each item were dichotomized as "No" (reported 0 times) or "Yes" (reported 1 or more times).

Sexual assault was measured using a single dichotomous item: "Have you ever been forced to have sexual intercourse when you did not want to?" The prevalence of recent self-directed violence was assessed using 3 survey items: (1) "During the past 12 months, did you ever seriously consider attempting suicide?" (2) "During the past 12 months, did you make a plan about how you would attempt suicide?" and (3) "During the past 12 months, how many times did you actually attempt suicide?" Responses for each 
item were dichotomized as "No" (reported 0 times) or "Yes" (reported 1 or more times).

Questions that refer to the past 30 days have 5 possible responses: "0 days," "1 day," "2 or 3 days," " 4 or 5 days," and "6 or more days." Questions that refer to the past 12 months have 8 possible responses: "0 times," "1 time," "2 or 3 times," "4 or 5 times," "6 or 7 times," "8 or 9 times," "10 or 11 times," and "12 or more times."

Participants' sociodemographic characteristics including age, sex, and race/ethnicity are selfreported. In the current analyses, the ethnicity and race items were collapsed to generate the following categories: non-Hispanic white, Hispanic, black or African American, Asian, and other. The "other" category was comprised of students who self-identified as more than 1 race, American Indian or Alaskan Native, Native Hawaiian or other Pacific Islander.

\section{Data Analysis}

Statistical analyses were conducted on weighted data using SAS version 9.4. PROC SURVEY procedures (SAS Institute, Inc., Cary, NC) were used to account for the complex sampling design. Sampling errors were estimated by using the primary sampling units and strata provided in the data and calculated through Taylor series linearization. Sampling weights were used to adjust for nonresponse and oversampling, and to allow for generalizability of findings to the population of high school students in Philadelphia. Univariate descriptive analyses were conducted to examine demographic characteristics of the study population. Individual multivariable regression models controlling for age, race/ethnicity, and accounting for sampling strategy were then developed to examine the prevalence of violent behaviors across the study years (2003, 2007, 2009, 2011 , and 2013). Linear and quadratic trend tests were used to identify trends in prevalence of each outcome between 2003 and 2013, and were identified as statistically significant at the alpha $<0.05$ level. Analyses were stratified by sex due to a priori hypotheses regarding differences in violence prevalence and trends by sex.

\section{RESULTS}

\section{Trends in Community Violence}

Among high school girls in Philadelphia, in 2013, $32.7 \%$ reported being in a fight in the past year, $8.7 \%$ reported carrying any weapon in the past year, and $1.7 \%$ stated they had carried a gun in the past 30 days. No significant changes in involvement in these types of community violence were observed over the 10-year study period (Table 2; Figure 1A). Among boys, in $2013,38.4 \%$ reported being in a physical fight in the past year, $15.7 \%$ reported carrying any weapon in the past month, and $6.8 \%$ reported carrying a gun (Table 3). All of these community violence-related behaviors showed significant declines in prevalence between 2003 and 2013, with the greatest reduction observed in physical fighting (48.8\% in 2003 to $38.4 \%$ in 2013; $\beta=-0.35, \mathrm{p}=.001$; Figure 1B). A significant quadratic trend was identified for physical fighting among boys and girls.

\section{Trends in School Violence}

For both boys and girls, the prevalence of involvement in violence in school remained stable over the 10-year observation period. Among girls in $2013,15.1 \%$ reported being in a physical fight in school in the past 12 months, $4.5 \%$ were threatened with a weapon at school in the past 12 months, and $2.2 \%$ carried a weapon in school in the past 30 days. In 2011,1 in $10(10.1 \%)$ girls reported staying home from school in the past 30 days because they felt unsafe (Table 2; Figure 1C). In 2013, 18.2\% of boys had been in a physical fight at school in the past 12 months, $9.2 \%$ had been threatened with a weapon in school in the past 12 months, and $3.5 \%$ of boys reported carrying a weapon to school in the past 30 days. In $2011,8.0 \%$ had stayed at home from school because of feeling unsafe at school (Table 3; Figure 1D). A significant quadratic trend was identified for physical fighting at school among boys.

\section{Trends in Sexual Assault and Self-Directed Violence}

In $2013,10 \%$ of girls reported that they had ever been forced to have sex; a statistically significant decline in experience of forced sex was observed among girls from 2003 when the prevalence was $14.6 \%(\beta=-0.13, \mathrm{p}=.04$; Table 2; Figure $1 \mathrm{E})$. In $2013,16.8 \%$ of girls reported that they had considered suicide, $13.6 \%$ made a suicide plan, and $9 \%$ reported a suicide attempt in the past year. The prevalence of suicide attempts among girls significantly declined between 2003, when the prevalence was $13.7 \%$, and 2013 ( $\beta=-0.14, \mathrm{p}=.007$; Table 2; Figure 1G). Among high school boys in Philadelphia, 6.9\% reported ever being forced to have sex; no significant change in the prevalence of forced sex among boys was observed over the 10 -year study period $(\beta=-0.12$, $\mathrm{p}=.12$; Table 3; Figure $1 \mathrm{~F}$ ). Reports of self-directed violence among boys in 2013 were as follows: $8.2 \%$ considered suicide, $8.4 \%$ made a suicide plan, and $10.4 \%$ attempted suicide. No significant changes in the prevalence of these outcomes were observed over the study period (Table 3; Figure 1H).

\section{DISCUSSION}

Interpersonal and self-directed violence remains one of the leading causes of death among youth 
Table 2. Self-Reported Violence-Related Behaviors Among Female High School Students, Philadelphia Youth Risk Behavior Survey, 2003-2013*

\begin{tabular}{|c|c|c|c|c|c|c|}
\hline Variable & $\begin{array}{l}2003 \\
\%(S E)\end{array}$ & $\begin{array}{l}2007 \\
\%(S E)\end{array}$ & $\begin{array}{l}2009 \\
\%(S E)\end{array}$ & $\begin{array}{l}2011, \\
\%(S E)\end{array}$ & $\begin{array}{l}2013 \\
\%(S E)\end{array}$ & $\begin{array}{l}\beta \text { estimate } \\
\left(P_{\mathrm{df}}=104\right)\end{array}$ \\
\hline \multicolumn{7}{|l|}{ Community violence } \\
\hline Carried any weapon in past 30 days & $11.1(0.01)$ & $11.4(0.01)$ & $10.8(0.01)$ & $9.9(0.01)$ & $8.7(.009)$ & $-0.09(0.08)$ \\
\hline Carried a gun in past 30 days & $2.1(0.005)$ & $1.7(0.005)$ & $2.0(0.007)$ & $1.5(0.005)$ & $1.7(0.005)$ & $-0.01(0.58)$ \\
\hline Physical fight in past 12 months & $33.3(0.02)$ & $41.1(0.02)$ & $41.5(0.02)$ & $38.2(0.02)$ & $32.7(0.03)$ & $-0.05(0.65)^{\dagger}$ \\
\hline \multicolumn{7}{|l|}{ School violence } \\
\hline Carried weapon in school in past 30 days & $3.2(0.006)$ & $2.8(0.005)$ & $2.9(0.007)$ & $2.7(0.007)$ & $2.2(0.005)$ & $-0.03(0.19)$ \\
\hline Threatened with weapon in school in past 12 months & $5.6(0.01)$ & $7.0(0.007)$ & $5.9(0.01)$ & $8.0(0.01)$ & $4.5(0.01)$ & $-0.02(0.57)$ \\
\hline Physical fight in school in the past 12 months & $14.0(0.02)$ & $16.0(0.01)$ & $15.3(0.02)$ & $16.6(0.02)$ & $15.1(0.02)$ & $0.03(0.62)$ \\
\hline Missed school because felt unsafe in past 30 days & $10.1(0.01)$ & $9.1(0.01)$ & $9.9(0.01)$ & $10.1(0.01)$ & - & $0.01(0.86)$ \\
\hline \multicolumn{7}{|l|}{ Sexual assault } \\
\hline Ever forced to have sex & $14.6(0.01)$ & $10.7(0.01)$ & $12.8(0.01)$ & $11.6(0.01)$ & $10.0(0.02)$ & $-0.13(0.04)$ \\
\hline \multicolumn{7}{|l|}{ Self-directed violence } \\
\hline Considered suicide in past 12 months & $18.8(0.02)$ & $18.0(0.01)$ & $18.5(0.02)$ & $17.3(0.01)$ & $16.8(0.02)$ & $-0.07(0.33)$ \\
\hline Made a suicide plan in the past 12 months & $16.1(0.01)$ & $14.6(0.01)$ & $16.0(0.02)$ & $12.7(0.01)$ & $13.6(0.02)$ & $-0.09(0.22)$ \\
\hline Attempted suicide in the past 12 months & $13.8(0.02)$ & $12.2(0.01)$ & $14.4(0.02)$ & $13.0(0.01)$ & $9.0(0.01)$ & $-0.14(0.007)$ \\
\hline
\end{tabular}

$\mathrm{SE}$, standard error.

*Model adjusted for students' age, race/ethnicity, and complex sampling strategy.

${ }^{\dagger}$ A significant quadratic trend was noted for this outcome.

in spite of recent reductions in its prevalence on a national level. ${ }^{1}$ To date, surveillance of youth violence has been largely conducted at the national and state level. ${ }^{1,31,32}$ These macro-level examinations may misrepresent trends in violent behaviors at the local level, especially among low-income, minority urban youth, who may be directly or indirectly involved in multiple types of violence in their schools and communities. ${ }^{33}$ Furthermore, youth violence reduction initiatives are primarily implemented at the local level; thus, their influence on youth violence may not be captured by national surveillance, highlighting the additional need for local-level surveillance. The results from this study indicate declines in several types of violence among Philadelphia high school students over the past decade; however, involvement in violence remained common. Overall, the high prevalence of specific violent behaviors, such as physical fighting, among Philadelphia adolescents puts these youth at particularly high risk for numerous negative behavioral, academic, and health outcomes including mental health problems and substance use. ${ }^{34}$

Among Philadelphia's high school students, a decrease in the prevalence of sexual assaults was observed among girls. Over the same period, national YRBS data did not identify a significant change in the prevalence of sexual assault among youth. ${ }^{1}$ This suggests that changing contexts specific to Philadelphia, including targeted sexual assault reduction campaigns, may play a role in the observed local-level reductions. For example, during the time frame of this study, local organizations such as Women Against Abuse and Women Organized Against Rape initiated teen dating violence prevention programs in the community and Philadelphia public schools. ${ }^{27,35}$ Whereas the observed declines are encouraging, the prevalence of sexual assaults among high school girls in Philadelphia remains higher than other large urban areas such as Chicago, San Diego, and Seattle, ${ }^{1}$ indicating that additional prevention and intervention programs are needed if these reductions are to continue.

Significant decreases in the prevalence of suicide attempts by high school girls were observed, which is consistent with overall trends from national data over the past 20 years. ${ }^{1}$ With these declines, the prevalence of suicide attempts among boys and girls in Philadelphia are now nearly equal, but suicidal ideation is still more prevalent among girls. Historically, the prevalence of suicide attempts and ideation among girls is consistently higher than among boys. ${ }^{1,36}$ Furthermore, girls who attempt suicide are more likely than boys who attempt suicide to have experienced sexual abuse, family dysfunction, anxiety disorders, low self-esteem, and dating violence. ${ }^{37,38}$ This suggests that suicide prevention programming in schools should be sensitive to potential sex differences in suicide risk factors if they are to be effective. With the passage of Act 71 in Pennsylvania in $2014,{ }^{39}$ which requires schools to adopt a youth suicide awareness and prevention policy as of 2015-2016, it is possible that local surveillance mechanisms can detect greater declines in youth self-directed violence following its implementation.

One of the most prevalent violent behaviors among girls and boys during the study period was physical fighting in the community and at school. The prevalence of physical fighting among girls and boys in Philadelphia is the third and fourth highest in the nation among youth in major cities, respectively. ${ }^{1}$ Compared to boys, there are few 
Figure 1. Violence Trends Among Philadelphia High School Girls (A, C, E, G) and Boys (B, D, F, H)
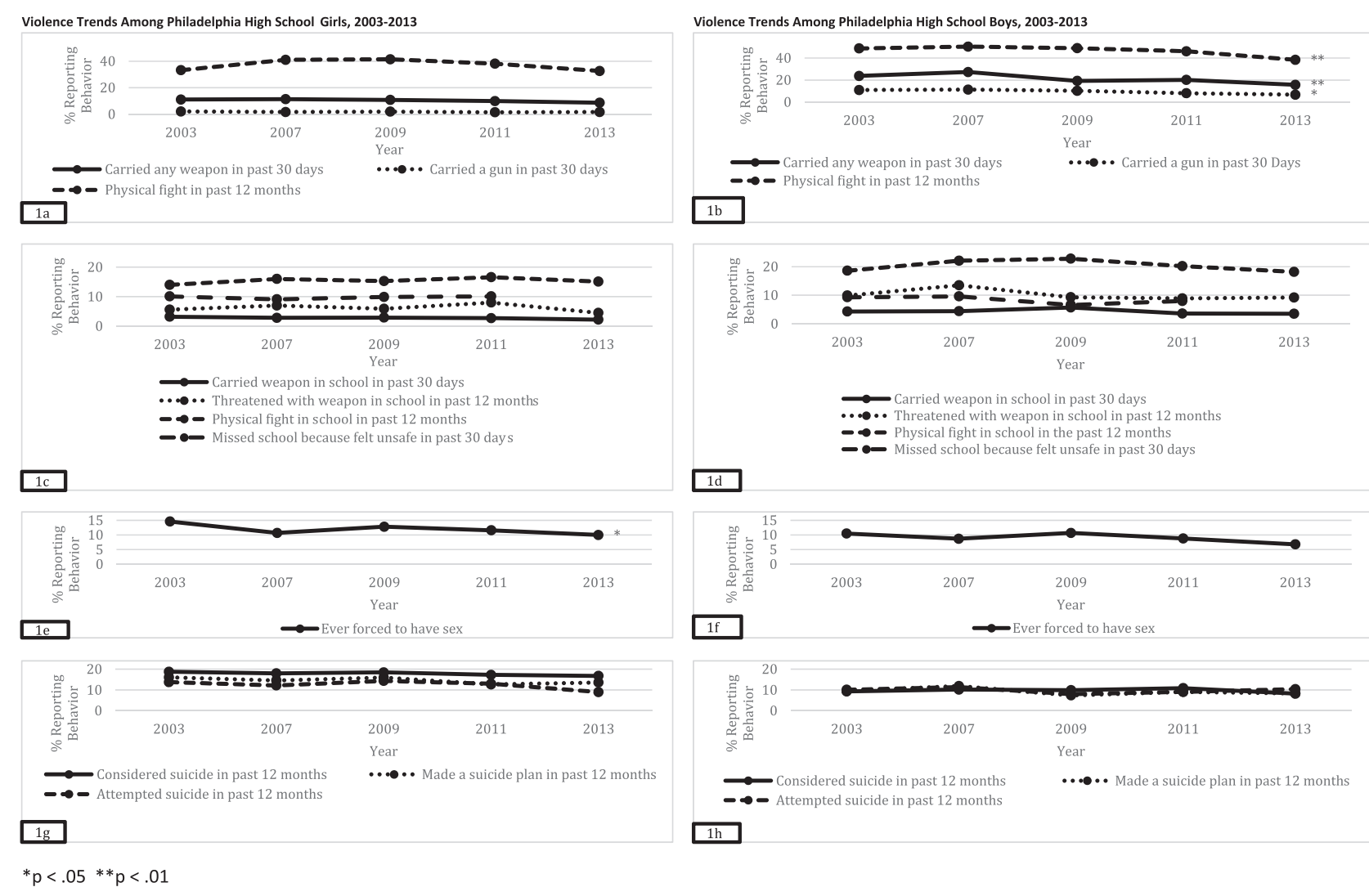

$* p<.05 * * p<.01$

Table 3. Self-Reported Violence-Related Behaviors Among Male High School Students, Philadelphia Youth Risk Behavior Survey, 2003-2013*

\begin{tabular}{|c|c|c|c|c|c|c|}
\hline Variable & $\begin{array}{l}2003 \\
\% \text { (SE) }\end{array}$ & $\begin{array}{l}2007 \\
\%(S E)\end{array}$ & $\begin{array}{l}2009 \\
\%(S E)\end{array}$ & $\begin{array}{l}\text { 2011, } \\
\% \text { (SE) }\end{array}$ & $\begin{array}{l}2013, \\
\%(S E)\end{array}$ & $\begin{array}{l}\beta \text { estimate } \\
\left(P_{\mathrm{df}}=104\right)\end{array}$ \\
\hline \multicolumn{7}{|l|}{ Community violence } \\
\hline Carried any weapon in past 30 days & $23.8(0.02)$ & $27.3(0.02)$ & $19.3(0.02)$ & $20.2(0.02)$ & $15.7(0.02)$ & $-0.31(<.001)$ \\
\hline Carried a gun in past 30 days & $11.0(0.02)$ & $11.4(0.01)$ & $10.3(0.02)$ & $8.1(0.01)$ & $6.8(0.01)$ & $-0.16(0.01)$ \\
\hline Physical fight in past 12 months & $48.8(0.02)$ & $50.4(0.02)$ & $49.0(0.03)$ & $46.2(0.03)$ & $38.4(0.02)$ & $-0.35(0.001)^{\dagger}$ \\
\hline \multicolumn{7}{|l|}{ School violence } \\
\hline Carried weapon in school in past 30 days & $4.3(0.007)$ & $4.4(0.008)$ & $5.7(0.01)$ & $3.6(0.008)$ & $3.5(0.007)$ & $-0.03(0.36)$ \\
\hline Threatened with weapon in school in past 12 months & $9.9(0.01)$ & $13.5(0.01)$ & $9.3(0.01)$ & $8.9(0.01)$ & $9.2(0.02)$ & $-0.07(0.29)$ \\
\hline Physical fight in school in the past 12 months & $18.6(0.02)$ & $22.1(0.02)$ & $22.8(0.02)$ & $20.2(0.02)$ & $18.2(0.02)$ & $-0.03(0.71)^{\dagger}$ \\
\hline Missed school because felt unsafe in past 30 days & $9.3(0.01)$ & $9.6(0.01)$ & $6.6(0.01)$ & $8.0(0.01)$ & - & $-0.06(0.20)$ \\
\hline \multicolumn{7}{|l|}{ Sexual assault } \\
\hline Ever forced to have sex & $10.5(0.02)$ & $8.7(0.01)$ & $10.7(0.02)$ & $8.8(0.01)$ & $6.8(0.01)$ & $-0.11(0.12)$ \\
\hline \multicolumn{7}{|l|}{ Self-directed violence } \\
\hline Considered suicide in past 12 months & $9.3(0.01)$ & $10.2(0.01)$ & $9.9(0.02)$ & $10.9(0.01)$ & $8.2(0.01)$ & $-0.03(0.57)$ \\
\hline Made a suicide plan in the past 12 months & $9.5(0.01)$ & $11.9(0.01)$ & $7.4(0.01)$ & $9.1(0.01)$ & $8.4(0.01)$ & $-0.06(0.26)$ \\
\hline Attempted suicide in the past 12 months & $10.1(0.02)$ & $11.4(0.02)$ & $8.0(0.02)$ & $9.1(0.01)$ & $10.4(0.02)$ & $-0.01(0.83)$ \\
\hline
\end{tabular}

$\mathrm{SE}$, standard error.

* Model adjusted for students' age, race/ethnicity, and complex sampling strategy.

${ }^{\dagger}$ A significant quadratic trend was noted for these outcomes. 
evidence-based intervention approaches to specifically address physical fighting among girls, which represents an important gap in public health initiatives. ${ }^{40}$ Given the high prevalence of fighting in school and the community observed in this study, and the significant proportion of youth who report skipping school due to fear of violence, further research is needed to identify effective ways to improve students' safety in school and the larger community.

Despite the high prevalence of physical fighting among boys, declines were observed in all types of community violence among boys during the study period. This finding is consistent with national trends, which demonstrate significant decreases in these 2 types of violent behavior over the past 20 years. ${ }^{1}$ Reducing violence among adolescent boys has been a key objective for Philadelphia during the time frame of this study, especially in the African American community, which has a disproportionally high homicide rate. ${ }^{27,41}$ Specifically, the city initiated the "Blueprint for a Safer Philadelphia" in 2004 and expanded the Youth Risk Violence Reduction Partnership - an intervention program for high-risk youth - to additional neighborhoods, with a focus on young male African Americans. ${ }^{42-44}$ The results of this study suggest that these initiatives along with other efforts across the city may be achieving some success in reducing violent behaviors in this group. Philadelphia intends to further decrease the prevalence of community violence by fully implementing additional evidence-based intervention programs such as Ceasefire, which has reduced gun violence among youth in other major cities. ${ }^{27,45,46}$ Continued monitoring of violence among male adolescents in Philadelphia would help elucidate the success of consistently and newly implemented initiatives and highlight areas in need of additional intervention.

A high proportion of adolescent boys reported being forced to have sex and the prevalence of this violent behavior did not significantly change during the time frame of this study; yet, this problem receives little attention. Adolescent boys are likely to underreport experiencing sexual abuse due to feeling stigmatized for not meeting social norms and expectations for them to be independent and skilled in interpersonal relationships. ${ }^{47-49}$ Thus, we hypothesize that the prevalence of forced sex reported in this study is an underestimate of the true level of sexual assault experienced by adolescent boys. Study findings highlight that sexual abuse prevention and intervention strategies designed specifically for boys are needed in schools, especially in urban areas, to reduce violence involvement as well as the stigma surrounding this problem and improve health outcomes for victims.

\section{Limitations}

Although this study had numerous strengths, including a sampling strategy that allows for generalizability of study findings to all Philadelphia high school students and inclusion of several types of violent behaviors across multiple locations, some study limitations exist. Results from this analysis are subject to the methodological limitations of the YRBS survey including the use of self-reported, single-item measures to assess behavior. For example, behaviors categorized as community-based violence could have occurred in schools, as these questionnaire items do not specify the location of the behavior. In addition, the prevalence of violent behaviors may be underestimated because youth who engage in violent behaviors may not attend school consistently or may have dropped out of high school. Whereas for almost all questions, the prevalence of missing data was low $(\sim 3 \%)$, a large proportion of students $(\sim 20 \%)$ did not complete the survey item regarding attempting suicide. It is likely that stigma or fear of reporting this behavior contributed to students skipping this question, and therefore the prevalence of this outcome may be higher than observed in this study. Despite these limitations, the high prevalence of self-reported involvement in violence among Philadelphia youth demonstrates the pressing need for ongoing research and intervention.

\section{Conclusions}

The prevalence of involvement in violence by adolescents has stabilized and, for some outcomes, declined in Philadelphia from 2003 to 2013. However, the prevalence of many types of violence remains higher among Philadelphia youth than among youth state or nationwide. Local, culturally specific efforts to reduce youth violence as well as larger initiatives and changes in community characteristics and resources may be contributing to the declines in violence prevalence observed in this study. The findings from this study support prioritizing specific violent behaviors as intervention targets, such as physical fighting among girls and sexual violence victimization among boys, which have been less of a focus of violence reduction efforts to date. Furthermore, continued local-level, comprehensive surveillance in Phil \textbf\{a\}adelphia and other areas of high risk is needed and contributes to our larger understanding of the etiology and outcomes of youth violence.

\section{IMPLICATIONS FOR SCHOOL HEALTH}

Some declines in youth violence were observed in this study, specifically community violence-related behaviors perpetrated by boys and suicide attempts and sexual assaults experienced by girls. However, the school violence-related behaviors examined in this 
study remained stable for both boys and girls. To decrease the prevalence of these behaviors, evidencebased youth violence reduction initiatives that have demonstrated effectiveness in the community may need an enhanced presence in schools. For example, Ceasefire programming could be translated to schools to expand their reach and potentially reduce youth violence in schools. Given limited resources available to many school districts, including Philadelphia, greater involvement from charitable organizations may be needed to support effective trainings for teachers, such as the United Way's funding of a Childhood Trauma Studies certificate offered by Philadelphia University. ${ }^{50}$ These trainings, coupled with evidence-based programs like Youth Mental Health First Aid ${ }^{51}$ and Helping Traumatized Children Learn, ${ }^{52}$ could create safer school environments for both students and staff by mitigating the association between adverse childhood experiences and engaging in violent behaviors.

The prevalence of violence among youth is still high, especially for behaviors that are not typically the focus of prevention and intervention, such as sexual assaults experienced by boys. To improve these outcomes, continued surveillance and development of novel, cost-effective, and evidence-based violence reduction initiatives are needed in schools. Comprehensive programs like Safe Dates have been shown to costeffectively reduce these violent behaviors in other US schools and should be empirically tested in Philadelphia schools. ${ }^{53,54}$

\section{Human Subjects Approval Statement}

The Temple University Institutional Review Board approved this study.

\section{REFERENCES}

1. Kann L, Kinchen S, Shanklin SL, et al. Youth Risk Behavior Surveillance-United States, 2013. MMWR Suppl. 2014;63 (suppl 4):1-168.

2. US Department of Health and Human Services, Office of Disease Prevention and Health Promotion. Healthy People 2020. Available at: http://www.healthypeople.gov/2020/topicsobjectives/topic/injury-and-violence-prevention/objectives. Accessed July 7, 2015.

3. US Centers for Disease Control and Prevention, National Center for Injury Prevention and Control. Web-based Injury Statistics Query and Reporting System (WISQARS). Available at: WwW .cdc.gov/injury/wisqars. Accessed July 7, 2015.

4. Ford JL, Browning CR. Effects of exposure to violence with a weapon during adolescence on adult hypertension. Ann Epidemiol. 2014;24(3):193-198.

5. Suglia SF, Sapra KJ, Koenen KC. Violence and cardiovascular health: a systematic review. Am J Prev Med. 2015;48(2):205-212.

6. Schwartz D, Gorman AH. Community violence exposure and children's academic functioning. J Educ Psychol. 2003;95(1): 163-173.

7. Kilpatrick DG, Ruggiero KJ, Acierno R, Saunders BE, Resnick HS, Best CL. Violence and risk of PTSD, major depression, substance abuse/dependence, and comorbidity: results from the National Survey of Adolescents. J Consult Clin Psychol. 2003;71(4):692-700.

8. Basch CE. Healthier students are better learners: a missing link in school reforms to close the achievement gap. J Sch Health. $2011 ; 81(10): 593-598$.

9. Evans GW. The environment of childhood poverty. Am Psychol. 2004;59(2):77-92.

10. Wade R, Shea JA, Rubin D, Wood J. Adverse childhood experiences of low-income urban youth. Pediatrics. 2014;134(1): e13-e20.

11. Joe S, Kaplan MS. Suicide among African American men. Suicide Life Threat Behav. 2001;31 (suppl s1):106-121.

12. Melhem NM, Day N, Shear MK, Day R, Reynolds CF III, Brent D. Traumatic grief among adolescents exposed to a peer's suicide. Am J Psychiatry. 2004;161(8):1411-1416.

13. Walker RL, Lester D, Joe S. Lay theories of suicide: an examination of culturally relevant suicide beliefs and attributions among African Americans and European Americans. J Black Psychol. 2006;32(3):320-334.

14. Morrison LL, Downey DL. Racial differences in self-disclosure of suicidal ideation and reasons for living: implications for training. Cultur Divers Ethnic Minor Psychol. 2000;6(4):374-386.

15. Pisani AR, Wyman PA, Petrova M, et al. Emotion regulation difficulties, youth-adult relationships, and suicide attempts among high school students in underserved communities. $J$ Youth Adolesc. 2013;42(6):807-820.

16. Swahn MH, Ali B, Bossarte RM, et al. Self-harm and suicide attempts among high-risk, urban youth in the US: shared and unique risk and protective factors. Int J Environ Res Public Health. 2012;9(1):178-191.

17. Olshen E, McVeigh KH, Wunsch-Hitzig RA, Rickert VI. Dating violence, sexual assault, and suicide attempts among urban teenagers. Arch Pediatr Adolesc Med. 2007;161(6):539-545.

18. Wolitzky-Taylor KB, Ruggiero KJ, Danielson CK, et al. Prevalence and correlates of dating violence in a national sample of adolescents. J Am Acad Child Adolesc Psychiatry. 2008;47(7):755-762.

19. Rennison CM. Rape and sexual assault: reporting to police and medical attention, 1992-2000. Available at: http://www.bjs .gov/content/pub/pdf/rsarp00.pdf. Accessed June 6, 2016.

20. McCauley JL, Conoscenti LM, Ruggiero KJ, Resnick HS, Saunders BE, Kilpatrick DG. Prevalence and correlates of drug/alcohol-facilitated and incapacitated sexual assault in a nationally representative sample of adolescent girls. J Clin Child Adolesc Psychol. 2009;38(2):295-300.

21. Tomasula JL, Anderson LM, Littleton HL, Riley-Tillman TC. The association between sexual assault and suicidal activity in a national sample. Sch Psychol Q. 2012;27(2):109-119.

22. Young AM, Grey M, Boyd CJ. Adolescents' experiences of sexual assault by peers: prevalence and nature of victimization occurring within and outside of school. $J$ Youth Adolesc. 2009;38(8):1072-1083.

23. O'Keefe M, Treister L. Victims of dating violence among high school students. Are the predictors different for males and females? Violence Against Women. 1998;4(2):195-223.

24. Hickman LJ, Jaycox LH, Aronoff J. Dating violence among adolescents: prevalence, gender distribution, and prevention program effectiveness. Trauma Violence Abuse. 2004;5(2): 123-142.

25. US Census Bureau. American FactFinder. Available at: http://factfinder.census.gov/faces/tableservices/jsf/pages/ productview.xhtml?src=bkmk. Accessed July 7, 2015.

26. The Pew Charitable Trusts. Philadelphia 2015: The State of the City. Available at: http://www.pewtrusts.org/ /media/ Assets/2015/05/2015-State-of-the-City-Report_Web.pdf? la=en. Accessed July 7, 2015.

27. Philadelphia Co. Philadelphia's strategic plan to prevent youth violence. Available at: http://www.phila.gov/Newsletters/ 
Youth_Violence_Strategic_Plan_\%20FINAL\%20September \%202013.pdf. Accessed July 7, 2015.

28. Brener ND, Kann L, Shanklin S, et al. Methodology of the Youth Risk Behavior Surveillance System - 2013. MMWR Recomm Rep. 2013;62 (RR-1):1-20.

29. US Centers for Disease Control and Prevention. YRBS participation, data quality, and data availability. Available at: http://www.cdc.gov/healthyyouth/data/yrbs/pdf/2013_hs_ participation_history.pdf. Accessed July 7, 2015.

30. School District of Philadelphia. About us - district schools. Available at: http://www.phila.k12.pa.us/about/\#schools. Accessed July 7, 2015.

31. Finkelhor D, Shattuck A, Turner HA, Hamby SL. Trends in children's exposure to violence, 2003 to 2011. JAMA Pediatr. 2014;168(6):540-546.

32. Vagi KJ, O'Malley Olsen E, Basile KC, Vivolo-Kantor AM. Teen dating violence (physical and sexual) among US high school students: findings from the 2013 National Youth Risk Behavior Survey. JAMA Pediatr. 2015;169(5):474-482.

33. United States Department of Agriculture, Service ER. Child poverty. Available at: http://www.ers.usda.gov/topics/ruraleconomy-population/rural-poverty-well-being/child-poverty .aspx. Accessed July 7, 2015.

34. Hawker DS, Boulton MJ. Twenty years' research on peer victimization and psychosocial maladjustment: a meta-analytic review of cross-sectional studies. J Child Psychol Psychiatry. 2000;41(4):441-455.

35. Women Against Abuse. Annual Report. Available at: http:// www.womenagainstabuse.org/images/uploads/assets/WAAAnnual-Report-Web.pdf. Accessed July 9, 2015.

36. Hawton K, Saunders KE, O'Connor RC. Self-harm and suicide in adolescents. Lancet. 2012;379(9834):2373-2382.

37. Ackard DM, Eisenberg ME, Neumark-Sztainer D. Long-term impact of adolescent dating violence on the behavioral and psychological health of male and female youth. J Pediatr. 2007;151(5):476-481.

38. Chatterji P, Dave D, Kaestner R, Markowitz S. Alcohol abuse and suicide attempts among youth. Econ Hum Biol. 2004;2(2): 159-180.

39. Public School Code of 1949 - Youth Suicide and Prevention and Child Exploitation Awareness Education. Harrisburg: Commonwealth of Pennsylvania Legislature; 2014.

40. Massetti GM, Vivolo AM, Brookmeyer K, et al. Preventing youth violence perpetration among girls. J Womens Health (Larchmt). 2011;20(10):1415-1428.

41. Philadelphia Department of Public Health. Community Health Assessment. Available at: http://www.phila.gov/health/pdfs/ CHAreport_52114_final.pdf. Accessed July 9, 2015.
42. McClanahan WS. Alive at 25: Reducing Youth Violence Through Monitoring and Support. Philadelphia, PA: Public/Private Ventures; 2004.

43. McClanahan WS, Kauh TJ, Manning AE, Campos P, Farley C. Illuminating Solutions: The Youth Violence Reduction Partnership. Philadelphia, PA: Public/Private Ventures; 2012.

44. Office of the District Attorney, City of Philadelphia. Blueprint for a safer Philadelphia. Available at: http://www.phila.gov/ districtattorney/crimePrevention_BluePrint.html. Accessed July 9, 2015.

45. Webster DW, Whitehill JM, Vernick JS, Curriero FC. Effects of Baltimore's Safe Streets Program on gun violence: a replication of Chicago's CeaseFire Program. J Urban Health. 2013;90(1): 27-40.

46. Skogan WG, Hartnett SM, Bump N, Dubois J. Evaluation of Ceasefire-Chicago. Available at: https://www.ncjrs.gov/ pdffiles1/nij/grants/227181.pdf. Accessed June 6, 2016.

47. Holmes WC, Slap GB. Sexual abuse of boys: definition, prevalence, correlates, sequelae, and management. JAMA. 1998;280(21):1855-1862.

48. Homma Y, Wang N, Saewyc E, Kishor N. The relationship between sexual abuse and risky sexual behavior among adolescent boys: a meta-analysis. J Adolesc Health. 2012;51(1): $18-24$.

49. Saewyc EM, Magee LL, Pettingell SE. Teenage pregnancy and associated risk behaviors among sexually abused adolescents. Perspect Sex Reprod Health. 2004;36(3):98-105.

50. United Way Worldwide. Healthy parenting. Available at: https://unitedforimpact.org/our-impact/education/earlychildhood-education/healthy-parenting. Accessed February 15, 2016.

51. Kelly CM, Mithen JM, Fischer JA, et al. Youth mental health first aid: a description of the program and an initial evaluation. Int J Ment Health Syst. 201 1;5(1):4.

52. Cole S, Greenwald O'Brien J, Gadd MG, Ristuccia J, Luray Wallace D, Gregory M. Helping traumatized children learn: supportive school environments for children traumatized by family violence. Available at: http://traumasensitiveschools .org/wp-content/uploads/2013/06/Helping-TraumatizedChildren-Learn.pdf. Accessed June 6, 2016.

53. Foshee VA, Reyes LM, Agnew-Brune CB, et al. The effects of the evidence-based Safe Dates dating abuse prevention program on other youth violence outcomes. Prev Sci. 2014;15(6):907-916.

54. Lanham JA. Efficacy and feasibilities of an evidence based program for seventh graders on teen dating violence: an evidence based nursing practice project. Available at: http://utdr.utoledo.edu/cgi/viewcontent.cgi?article $=1011 \mathrm{\delta}$ context=graduate-projects. Accessed July 29, 2015. 